\title{
CENOGRAFIA E ETHOS NA LINGUAGEM SOBRE TRABALHOA PARTIR DO PRESCRITO EM UM WEBSITE CORPORATIVO
}

Mateus Fonseca Pereira é mestrando em Letras na Universidade de Passo Fundo, possui graduação em Teologia pela Faculdade deTeologia Evangélica em Curitiba e em Design Gráfico pela Universidade Federal de Pelotas. E-mail: mateusfp@ hotmail.com

Ernani Cesar de Freitas é doutor em Letras (PUC-RS), com pós-doutorado em Linguística Aplicada e Estudos da Linguagem (PUC-SP/LAEL); professor permanente do PPGL da UPF. E-mail: ecesar@upf.br

\section{Resumo}

Esta análise objetiva-se em descrever e avaliar a constituiçãoda cenografia e do ethos por meio de práticas discursivas relacionadas à atividade no trabalho, a partir da cena de enunciação criada por uma empresa em um de seus websites corporativos. A abordagem teórica é de base enunciativo-discursiva, com ênfase na semântica global de Maingueneau mediante interface com estudos sobre linguagem e trabalho e a disciplina ergológica.

\begin{abstract}
This analysis aims at describing and evaluating the creation of scenography and ethos through discursive practices related to the work activity, from the enunciation scene created by a company in one of its corporate websites. The theoretical approach is discursive enunciation-based, with an emphasis on global semantics by Maingueneau through interface with studies on language and work and the ergological subject.
\end{abstract}

\section{1)Introdução}

Nos últimos anos tem crescido o número de publicações referentes ao estudo das relações entre situações de trabalho e linguagem, baseadas na ergonomia da atividade e nadisciplina ergológica. Isto se deve ao fato de que nunca se trabalha sozinho e logicamente há um processo comunicacional no ambiente de trabalho que é explicitado pelas diversas linguagens utilizadas nesse contexto, o que difere da concepção taylorista/fordista que consideram o trabalhador como um indivíduo dotado de uma cultura própria e uma capacidade de se diferenciar dos outros.

E justamente visando facilitar esta comunicação dentro das empresas, que se expandem em um contexto global, várias delas têm adotado as novas tecnologias de informação e comunicação (TICs) para aproximar seus funcionários, independente das hierarquias que ocupam dentro da organização. Isso tem ocorrido tanto pelaredução de custos quanto pela velocidade que as TICs proporcionam ao conectar os diversos empregados, principalmente através da internet.

Além disso, um fato interessante dessas TICs desenvolvidas para a Web $2.0^{1}$ é que elas possibilitam maior interação em uma verdadeira via de mão dupla na troca de informações, na qual não há apenas um detentor da palavra. Isso tem permitido que várias companhias, aquelas que realmente veem seus colaboradores como tais, deem um maior espaço para a voz e a opinião daqueles que geram o lucro. Contudo, mesmo com o uso das novas tecnologias comunicacionais, muitas outras empresas ainda agem nos moldes antigos em que apenas os níveis superiores têm voz.

Considerando este cenário,no qual a tecnologia está a serviço da comunicação no ambiente de trabalho, é importante verificar comotal processo é estabelecido quando há uma interação por meio da internet que, de alguma forma, simula a comunicação face a face utilizando as ferramentas proporcionadas pela Web 2.0, seja através de vídeos,

${ }^{1} \mathrm{O}$ termo Web 2.0 refere-se ao uso da tecnologia em sites da internet que vai além das páginas estáticas. Na Web 2.0 os usuários têm mais possibilidades de interação e criação compartilhada, sendo os sites chamados de redes sociais a grande expressão deste conceito. 
textos, programas de chat, etc. Com esse intuito, foi selecionado para análise owebsite institucional de uma empresa multinacional do ramo de educação e comunicação, que tem como objetivo informar seus colaboradores sobre questões na área educacional.

Assim, a partir de alguns textos veiculados neste website, pretende-se analisar a situação de trabalho vigente ali, avaliando mais especificamente: as características gerais desta mídia e as possibilidades de interação que ela proporciona; a situação de comunicação existente considerando o estabelecimento de uma cena de enunciação;a cenografia construída, destacando o ethos da empresa a partir de tais textos.

Para realizar esta tarefa, serão utilizados alguns estudos sobre linguagem e trabalho de Feitosa (1998), Lacoste (1998), Nouroudine (2002), Souza-e-Silva (2002) e Trinquet (2010), que tratam da questão do trabalho prescrito, da comunicação no ambiente de trabalho e dadisciplina ergológica,além de reflexões sobre ethos discursivo e práticas comunicacionais por meio da internet,conforme pressupostos da semântica global de Maingueneau (2006, 2008a, 2008b, 2008c, 2010, 2011).

Este artigo segue então estruturado da seguinte forma: primeiro serão abordadas questões referentes à linguagem no ambiente de trabalho e à disciplina ergológica. Após, serão trabalhados os conceitos de cenografia e ethos discursivo. Em seguida é apresentada a metodologia empregada e os procedimentos de análise, com um detalhamento ampliado do corpus. Finalmente, é apresentada a análise e algumas considerações finais com os resultados do estudo.

\section{2)A linguagem no ambiente de trabalho}

Aquilo que se entende hoje na sociedade capitalista como trabalho, ou atividade laboriosa, tem ganho cada vez mais destaque em diferentes áreas de pesquisa além da Administração. Isso porque já foi percebido que o ser humano, aquele que desenvolve uma atividade e tarefa, não pode ser considerado apenas como uma engrenagem do sistema automatizado das linhas de montagem. Diferente disso, já foi compreendido que para aumentarem seus lucros, as empresas devem respeitar cada indivíduo como um ser único e diferenciado dos demais, sendo que uma troca de funcionários nunca pode ser equiparada à simples reposição de peças de uma máquina. Porém, para chegar a essa compreensão, foram necessários vários anos de experiência empírica, com seus erros e acertos, até que diversas ciências se preocupassem de fato com a atividade de trabalho. Assim, houve uma benéfica ampliação de estudos nos últimos anos, englobando áreas do conhecimento como a psicologia, a antropologia, a sociologia, a medicina, a linguística, etc.

Toda essa mobilização deve-se ao fato de que vários saberes constituem uma situação de trabalho, sendo que a análise de uma determinada circunstância, através desses vários vieses, pode oportunizar sua compreensão de forma mais detalhada. É isto que afirma a ergonomia ${ }^{2}$, disciplina preocupada com a compreensão da interação entre seres humanos e outros elementos de um sistema. A forma como a ergonomia é compreendida atualmente, segundo a Ergoweb ${ }^{3}$, é originária dos tempos da Segunda

\footnotetext{
${ }^{2}$ Definição da International Ergonomics Association.

${ }^{3}$ Empresa que presta serviços na área de ergonomia.
} 
Guerra Mundial e também da Guerra Fria, devido aos grandes avanços tecnológicos que elas proporcionaram, principalmente com relação ao uso da computação e tecnologia digitais.

Contudo, justamente pelo fato de a ergonomia estar relacionada com a interação entre diferentes componentes de um sistema, sejam eles humanos ou não, há grande relação dela com a área da comunicação, seja esta visual ou verbal. Dessa forma, os estudos da linguagem no ambiente de trabalho ganharam destaque a partir da década de 1980, principalmente com as pesquisas realizadas na França por Alain Wisner, Yves Schwartz e Pierre Trinquet e,com estes, a adoção dadisciplina ergológica. Trinquet (2010, p. 94) ainda explica que a ergologia "não é uma nova disciplina das ciências humanas", mas sim "um método de investigação pluridisciplinar em função de a atividade humana ser muito complexa para se compreender e analisar a partir de uma única disciplina, qualquer que ela seja".

O uso da língua, ou as práticas linguageiras para alguns pesquisadores, ou ainda a atividade de linguagem para outros, está ligada de forma muito próxima à atividade de trabalho segundo Souza-e-Silva (2002, p. 61-76), pois ambas transformam o meio social e permitem trocas e negociações entre os seres humanos. Dessemodo,é através dessas trocas que o indivíduo se constitui como sujeito, quando faz o uso de si por si e assim se diferencia do outro, visto serpor meio da língua que cada um deixa-se conhecer e expressa sua cultura, seus valores,sua opinião. E é nesta situação limítrofe que vivem os sujeitos no ambiente de trabalho,porquanto lá fica clara a existência de um número de coerções que se apresentam em diferentes níveis. Essas coerções vêm, na sua grande parte, de fora, do outro, sejam elas impostas pelo ambiente, pela hierarquia entre funcionários, pela cultura da empresa, pela cultura dos outros colaboradores, etc.

Seguindo esta linha de pensamento, vale ressaltar que a dita conversa dentro do ambiente de trabalho, diferente da visão taylorista, não pode ser mais considerada como desvio de função, recusa de executar tarefas ou mesmo um mau procedimento, visto que a comunicação verbal faz parte de grande número de atividades relacionadas ao ambiente de trabalho e que são vitais para o funcionamento de uma empresa. Afinal, é através da fala que instruções são passadas, avaliações e reclamações são feitas e funções propriamente ditas são executadas. E com o intuito de compreender melhor como se constitui a linguagem no trabalho, Lacoste (1998, p. 15-36) propõe a distinção entre "linguagem como trabalho", "linguagem no trabalho" e "linguagem sobre o trabalho".

Nouroudine (2002, p. 17-30) desenvolve e explica melhor esses conceitos. Para ele, a "linguagem como trabalho" é tão complexa quanto toda atividade de trabalho, considerando que é através da linguagem que o pensamento é exteriorizado e explicitado, sendo este compreensível por outros ou não. A "linguagem no trabalho" vai além do plano estrito das tarefas e articula múltiplas dimensões da vida social, pois é "constitutiva da situação de trabalho global na qual se desenrola a atividade" (NOUROUDINE, 2002, p. 22). Já a "linguagem sobre o trabalho" é revelada no interior da atividade, por exigências da companhia ou de seus funcionários, e possibilita a transmissão de saberes dentre os membros de uma equipe. Em vários momentos 
Nouroudine (2002, p. 23-26) comenta que esta tripartição implica também em imbricações, mas isto não afeta sua distinção; diz o autor.

[...] partindo do pressuposto da existência de uma linguagem que faz (a linguagem como trabalho), uma linguagem circundante (linguagem no trabalho) e uma linguagem que interpreta (a linguagem sobre o trabalho), conduzir a análise das práticas de linguagem tendo em mente, ao mesmo tempo, suas distinções e suas imbricações revela-se adequada a uma melhor disponibilização do conhecimento a serviço da ação sobre o trabalho.(NOUROUDINE, 2002, p. 26).

Dito isso, é importante destacar ainda outros dois conceitos que estão ligados ao trinômio linguagemcomo, no e sobre o trabalho: o trabalho prescrito e o trabalho real, pois é também através da linguagem que eles se constituem. Esta distinção entre aquilo que é prescrito como tarefa e aquilo que é realizado como atividade real é importante por justamente permitir perceber que há uma distância permanente. Esta distância, cuja existência foi negada por muito tempo e por muitas pessoas, é um dos materiais de estudo que exige maior dedicação dos ergólogos e, por esta razão, a conceituação dos termos torna-se necessária.O trabalho prescrito, segundo Brito (2008, p. 440), "refere-se ao que é esperado no âmbito de um trabalho específico, com suas singularidades locais". Freitas (2011, p. 108) adiciona ainda que este "refere-se aos documentos que instruem, ensinam, aconselham etc. o trabalho a ser realizado. Instituições ou empresas os produzem anteriormente à realização efetiva do trabalho para representar o que deve (ou não) e como deve ser feito". O trabalho real é a atividade executada pelos trabalhadores em uma situação concreta, ao tentar responder às imposições externas (prescritas). Neste processo, os trabalhadores apreendem e modificam o prescrito através de sua atividade. Estas modificações e adaptações, as quais Trinquet (2010, p. 97) menciona como uso de si, auto-organização ou poder de agir, caracterizam a evolução do trabalho, o que corresponde à capacidade especificamente humana de usar a sua liberdade como convém, permitindo-lhe "escolher, adaptar-se, atualizar e, portanto, inovar" (TRINQUET, 2010, p.97).

Considerando ainda o enfoque que se pretende com este artigo, vale mencionar o estudo de Feitosa (1998, p. 37-50) referente a escritos de trabalho. A autora destaca em um primeiro momento a diferença entre a materialidade de textos orais e textos escritos, pois se caracterizam pela permanência ou efemeridade. Além disso, Feitosa (1998, p. 39) destaca que esta materialidade se dá tanto sob a forma linguística quanto sob a forma física (através do suporte material), o que possibilita sua reutilização. Estes escritos no sistema de trabalho configuram-se como escritos operacionais, gerenciais ou formativos. Os operacionais "permitem o desenvolvimento de sequências de ações" (FEITOSA, 1998, p. 40) - são os manuais de instrução, as listas de verificação, as elucidações feitas por um colega, etc. Os escritos gerenciais "existem em função do sistema organizacional” (FEITOSA, 1998, p. 41), sendo anteriores ou posteriores à cena de trabalho. Eles "estabelecem metas, objetivos, parâmetros, registram o trabalho realizado" (FEITOSA, 1998, p. 41) e apresentam-se como relatórios, contratos, projetos, circulares, etc. Já os escritos formativos estão relacionados com as competências dos trabalhadores necessárias para impulsionar o sistema técnico, com a 
finalidade de ampliar seus esquemas de conhecimento. Isto pode ser exemplificado ao se pensar nos materiais utilizados pelas empresas em treinamentos e para a formação contínua de seus funcionários.

Ao serem considerados os apontamentos feitos por Feitosa (1998) quanto aos escritos operacionais, gerenciais e formativos, pode-se perceber que é por meio deles que o trabalho prescrito é manifestado. Afinal, aquilo que é esperado do trabalhador, tanto refere-se a aspectos técnicos de execução de uma tarefa (operacional) quanto à obediência de normas institucionais (gerencial). E ainda há a possibilidade de que este mesmo trabalhador passe por treinamentose aperfeiçoamentos (formativo) devido a uma promoção, troca de função ou a uma atualização. Estas ideias referentes aos tipos de escritos como manifestação do trabalho prescrito serão retomadas posteriormente durante a análise do corpus proposto. A seguir serão abordados alguns conceitos referentes à semântica global, com destaque para as definições de cenografia e ethos discursivo, por serem fundamentais para a análise enunciativo-discursiva proposta neste estudo.

\section{3)Elementos da semântica global: cenografia e ethos}

\section{1)Da cena de enunciação à cenografia}

Ao afirmar que a atividade de trabalho também é constituída através do uso da língua e de práticas de linguagem, são necessários alguns referenciais linguísticos que possibilitem a análise mediante esse viés comunicacional. Dessa forma, são abordados aqui alguns pontos da semântica global desenvolvida por Maingueneau (2008a), pelo fato de esta valorizar o discurso e possibilitar uma abrangente compreensão de aspectos discursivos.

Como ponto de partida, dentro das teorias enunciativas e discursivas, considerase importante situar as noções de discurso e enunciação utilizadas, visto que constituem a base para o desenvolvimento dos outros conceitos abordados nesta seção. Assim, dentro do referencial da análise de discurso de linha francesa adotado, acredita-se ser coerente o emprego das postulações do próprio Dominique Maingueneau e outras que vão na mesma direção teórica. Portanto, para esse linguista francês, o discurso define diretrizes semânticas construídas por meio do estudo de grupo de textos, cuja superfície é apenas um meio para se atingir o nível discursivo (MAINGUENEAU, 2011). A convergência entre um sistema de regras semânticas com dispositivos retóricos (ethos e pathos, por exemplo) dentro de uma conjuntura histórica é responsável pela individualização de um discurso, o que será destacado a seguir com na abordagem da semântica global e o entrelaçamento dos planos que a constituem. Isso é de suma importância neste estudo, visto que "cada discurso define o estatuto que o enunciador deve atribuir a seu destinatário para legitimar o seu dizer" (MAINGUENEAU, 1984, p. 87).

Com relação a enunciação, Maingueneau recorre à Émile Benveniste ao afirmar que esta é um ato individual de utilização da língua, que se opõe ao enunciado, objeto linguístico resultante. Em seu Dicionário de Análise de Discurso, Charaudeau e Maingueneau (2012, p. 193) estabelecem a enunciação como "o pivô da relação entre a 
língua e o mundo", dado que "o enunciado só faz referência ao mundo na medida em que reflete o ato de enunciação que o sustenta”. Dessa forma tem-se que a noção linguística da enunciação diz respeito às operações constitutivas do enunciado, ou seja, os procedimentos que o sujeito realiza para se comunicar. Isso remete a situação de enunciação, a qual se trata de "um sistema de coordenadas abstratas, associadas a toda produção verbal" (CHARAUDEAU; MAINGUENEAU, 2012, p. 194).

Referente à semântica global, pode-se dizer que os enunciados que constituem o discurso apresentam vários planos integrados, que dizem respeito tanto ao próprio enunciado quanto à enunciação, sendo eles: a intertextualidade, o vocabulário, os temas, o estatuto do enunciador e do destinatário, a dêixis enunciativa, o modo de enunciação e o modo de coesão. Este estudo focará principalmente no estatuto do enunciador e do destinatário, na dêixis enunciativa e no modo de enunciação, pois esses planos constitutivos estão diretamente relacionados com a situação de enunciação na qual se pode chegar ao conhecimento de uma cenografia e um ethos discursivo da empresa a partir do website analisado.

Quando se fala em enunciador e destinatário está sendo feita referência às pessoas que fazem parte da situação de comunicação, partindo-se do pressuposto que todo o discurso estabelece um quadro enunciativo. Nesta situação, não está se falando de sujeitos empíricos, mas sim da imagem que cada uma destas pessoas projeta de si, as quais podem ser compreendidas com a depreensão de cada um dos ethé. Dessa forma ambos, enunciador e destinatário, estão ligados à cena de enunciação, sendo que cada um deles é legitimado com o seu dizer próprio.

E ao abordar a dêixis enunciativa, estão sendo referidos os traços que situam o discurso no tempo e no espaço. Conforme Maingueneau (2008a, p. 89), é a dêixis que "define de fato uma instância deenunciação legítima, delimita a cenae a cronologia que o discurso constróipara autorizar sua própria enunciação". Contudo, da mesma forma que o enunciador é uma pessoa criada no e pelo discurso, a dêixis não se refere amarcas empíricas; eladecretaum tempo (cronologia) e um espaço (cena) de acordo com as imposições de um discurso específico.

Já o modo de enunciação pode ser entendido como uma maneira de dizer específica, implicando que "o discurso produz um espaço ondese desdobra uma 'voz' que lhe é própria" (MAINGUENEAU, 2008a, p. 91). Esta 'voz' está relacionada com o tom, o caráter e a corporalidade específicos do enunciador, o que é construído na forma de representação subjetiva.

Segundo o conceito de cena de enunciação de Maingueneau (2006, p. 250),um texto se estabelece por meio do"rastro de um discurso em que a fala é encenada".Assim, "a encenação nada mais é do que as pistas deixadas por um enunciador que toma a palavra - [...] - e a partir dela o legitima e valida seu dizer" (FACIN, 2012, p. 50).A cena de enunciação compreende ainda três diferentes cenas: a cena englobante, a cena genérica e a cenografia. "Juntas, elascompõem um 'quadro' dinâmico quetorna possível a enunciação de um determinado discurso" (FREITAS, 2010, p.179). Maingueneau (2008b, p. 75) explica que a cena englobante corresponde ao tipo do discurso (político, religioso, educacional, filosófico, publicitário, etc.), o que the atribui um estatuto pragmático. A cena genérica está associada aos gêneros do discurso, o que aponta o 
estatuto genérico do enunciado, ou seja, se é um relatório, umaoração,um discurso, umaentrevista etc.

Porém, a cenografia é construída pelo texto, em um espaço que não é aquele físico, mas sim um ambiente delimitado pela enunciação. Ela envolve um processo de conexões contraditórias entre as cenas, em que o texto admite uma situação de enunciação que é validada à medida que a própria enunciação se consolida (MAINGUENEAU, 2011, p. 98). Assim sendo,

a cenografia é, ao mesmo tempo, aquilo de onde vem o discurso e aquilo que esse discurso engendra: ele legitima um enunciado que, por sua vez, deve legitimá-la, deve estabelecer que essa cena da qual vem a palavra é precisamente a cena requerida para enunciar nessa circunstância. (MAINGUENEAU, 2008b, p.70).

Facin (2012, p. 54) afirma que a cenografia tem forte ligação com o gênero discursivo, "uma vez que enunciação se constrói com um gênero", e este gênero permite antever a cenografia que será instaurada. Isto porque há casos nos quais são possíveis cenas enunciativas mais estáveis, como sãoos exemplos dos relatórios científicos e das receitas médicas, visto que estes "obedecem a certas prescrições impostas por um gênero de certo modo 'engessado'" (FACIN, 2012, p. 54). De maneira diferente, há gêneros discursivos mais maleáveis, que exigem obrigatoriamente a escolha de uma cenografia.

Desse modo, a razão pela mobilização da cenografia também diz respeito à noção de hipergênero, igualmente instituída por Maingueneau (2010). O autor francês (2010, p. 131) declara que essa noção "pode ser útil para estudar as práticas comunicacionais na internet", justamente o "local" onde está inserido o corpus deste estudo. Maingueneau (2010) faz esta declaração destacando que a internet é tanto este local onde surgem novos gêneros discursivos quanto o meio que altera as condições de comunicação, aquilo que pode ser considerado um gênero e também a noção de textualidade. Os hipergêneros então seriam aqueles gêneros que "enquadram uma larga faixa de textos e podem ser usados durante longos períodos e em muitos países", (MAINGEUNEAU, 2010, p.131), apresentando restrições muito pobres.

Isso ocorre, ainda segundo o mesmo autor (2010, p. 132), porque a noção clássica de gênero discursivo não leva em consideração a internet e, além disso, está baseada na concepção de cena de enunciação incluindo uma cena englobante e uma cena genérica. Porém a internet apresenta uma condição diferenciada, na qual as coerções dos gêneros são cada vez mais frágeis. Assim, no meio virtual, é a cenografia que tem o papel fundamental, visto que na internet "o problema principal é encenar a comunicação de acordo com as estratégias de seus produtores" (MAINGUENEAU, 2010, p. 133).

A seguir será abordada a questão do ethos discursivo.

\section{2) $O$ ethos discursivo}

A noção de ethos surgiu inicialmente nos escritos do filósofo grego Aristóteles sobre a retórica e, para ele, este conceito estariarestrito à persuasão, a qual configuraria o elemento constituinte da arte. Porém, neste artigo, o interesse não é pormenorizar o 
ethos retórico; a concepção de teoria e a posterior análise do corpus estão ligadas à concepção discursiva de ethos, advinda da semântica global, como mencionado anteriormente.

E ao fazer referência à semântica global também é importante salientar que nela não há o emprego direto da terminologia "ethos". Contudo, o plano constitutivo do discurso, chamado de modo de enunciação,disponibiliza propriedades características à concepção do ethos discursivo, sendo a postura/atitude do enunciador que estabelecerá seu modo de enunciação, isto é, o seu ethos. Assim, avançando nesta compreensão, o ethos refere-se a uma imagem de si por meio do discurso. "Dizer que os participantes do discursocriam uma autoimagem através dele significa também afirmar que o discurso carrega as marcas do enunciador e do coenunciador, entendidos aqui como aqueles que interagem no processo discursivo" (FREITAS, 2010, p. 180). Isto significa que tanto o enunciador quanto o coenunciador são constituídos na instauração do discurso. De qualquer forma, é necessário perceber que essas imagens não são desveladas de forma instantânea na leitura do texto, pois, ao criar um ethos para legitimar seu discurso, o enunciador tem o seu corpo construído e validado pelo próprio discurso.

Nesse contexto, a elaboração da corporalidade do enunciador está conectada com o ethos através de um tom atribuído pelo enunciador no plano do discurso (MAINGUENEAU, 2008b). Esse tom permite que o destinatário construa uma reprodução subjetiva do corpo do enunciador, o qual não é manifestado fisicamente, mas simplesmente elaborado como idealização abstrata.

Assim, sendo possível vislumbrar o corpo do enunciador, surge a figura do fiador, a qual nunca deve ser confundida com o autor efetivo, o comunicador real, pois esse fiador apresenta-se também exclusivamente no âmbito do discurso. A imagem criada desse fiador é comparável a um ser imaterial (porém não somente imaginário), o qual é formado por duas qualidades básicas: caráter e corporalidade. " $\mathrm{O}$ 'caráter' corresponde aum feixe de traços psicológicos. Já a 'corporalidade' é relacionadaa uma compleição física e a uma forma de sevestir. Além disso, a noção de ethos implica uma forma de mover-se no espaço social, uma disciplina tácita do corpo, apreendidapor meio de um comportamento" (MAINGUENEAU, 2008c, p. 65).

Então, após este corpo ser conferido ao fiador, ele é compreendido e captado pelo coenunciador e como resultado se obtém a eficácia do discurso, alcançadapor meio deste processo de incorporação. Segundo Maingueneau (2006, p. 200), a incorporação é a forma pela qual o coenunciador se apropria do ethos do discurso, o que acorre com a compreensão do "tom" da enunciação, o qual é elaborado mediante o entrelaçamento dos planos do discurso mencionados anteriormente (neste caso com o estatuto do enunciador e do destinatário, a dêixis enunciativa e o modo de enunciação). Esse tom então revela traços do caráter e da personalidade do enunciador.

Na próxima seção é detalhada a metodologia da análise e também o corpus a ser estudado.

\section{4)Metodologia}


A metodologia utilizada para a análise realizada neste artigo é exploratórioqualitativa, a partir de referências multidisciplinares que abordam as áreas de conhecimento envolvidas neste estudo, como a utilização da linguagem no ambiente de trabalho e o método ergológico nos textos de Feitosa (1998), Lacoste (1998), Nouroudine (2002), Souza-e-Silva (2002) e Trinquet (2010), e também aquilo que diz respeito ao conceito de semântica global e principalmente às noções de cenografia e ethos discursivo, em Maingueneau (2006, 2008a, 2008b, 2008c, 2010, 2011).

O corpus a ser analisado, owebsite do departamento educacional do Grupo $\mathrm{O}^{4}$, é um website institucional de uso restrito (necessita de nome de usuário e senha) aos funcionários deste departamento, que tanto trabalham na matriz da empresa ou em uma de suas franquias. O Grupo $\mathrm{O}$ é uma holding multinacional proprietária de várias marcas de escolas de inglês, editoras e outras empresas da área de comunicação.

Para uma melhor compreensão da utilização deste websitecomo corpus de pesquisa, além da razão de sua existência no âmbito da empresa, é necessário visualizar a estrutura do departamento de ensino do Grupo O. O departamento de pesquisa e desenvolvimento da empresa é responsável por gerir a questão do ensino, sendo que as suas três áreas de pesquisa, criação, revisão e o suporte educacional propõem práticas pedagógicas e questões a serem adotadas por todas as escolas da rede e serem seguidas pelos funcionários da área em questão. Assim, com este website, a empresa consegue um alcance mais fácil, rápido e econômico, considerando que há escolas do grupo espalhadas por seis países diferentes.

A escolha deste corpus se justifica tanto por se tratar de uma empresa que está em evidência no mercado de ensino da língua inglesa no país e no mundo (algumas de suas marcas estão relacionadas a grandes eventos internacionais), quanto por ser uma demonstração de novas formas de gerir o ensino, além de expor que há empresas fazendo grandes investimentos na área de educação em nosso país.

Talwebsite é constituído tanto por textos quanto por vídeos, sendo quesua análise contará com uma breve descrição para melhor situar o leitor com relação ao tipo de conteúdo disponível. Após isto será feita a avaliação de alguns aspectos discursivos de um texto e um vídeo encontrados no site, baseando-se nos conceitos dos planos da semântica global de Maingueneau, com o intuito de depreender a cenografia e o ethosdiscursivo criados pela empresa, na condição de enunciadora.

Para fins de melhor compreensão da análise, foram elaborados os seguintes procedimentos metodológicos,com destaque para a interface entre:

a) Disciplina ergológica: foram verificados os conceitos sobre linguagem no ambiente de trabalho, destacando a distinçãoentre "linguagem como trabalho", "linguagem no trabalho" e "linguagem sobre o trabalho". Ênfase no trabalho prescrito e no trabalho real constituídos pelo uso da linguagem, que se manifestam como escritos operacionais, gerenciais ou formativos nos quais há a "dramática do uso de si".

b) Abordagem enunciativo-discursiva da semântica global: destaque para a construção da cenografia e do ethos discursivo: o estatuto do enunciador e do

\footnotetext{
${ }^{4}$ Foram atribuídos nomes fictícios à empresa e aos colaboradores mencionados.
} 
coenunciador, dêixis enunciativa e modo de enunciação para descrever a cenografia enunciativa e o ethos construídos no website analisado, os quais são marcados linguisticamente por especificidades do dizer, ou seja, pela linguagem no ambiente de trabalho.

A seguir é exposta a análise a partir dosconceitos apresentados anteriormente.

\section{5)Análise}

$\mathrm{O}$ website do departamento de ensino do Grupo O é composto por textos e vídeos, um exemplo claro do conceito de escritos de trabalho de Feitosa (1998), ligados às diferentes realidades da empresa. Os textos, por exemplo, podem ser compreendidos como abordando informações em geral do departamento, podendo ser classificados ainda segundo uma concepção genérica mais tradicional na condição de cena genérica reportagem.Nesses textos, inclusive, são mencionados com frequência membros do departamento de pesquisa e desenvolvimento (diretor, coordenadores, etc.), sendo que há inclusive um dando destaque a um colaborador em particular.

Outra cena genérica que aparece com frequência no websiteé, ainda segundo a concepção de Feitosa (1998),o texto formativo, o qual é manifestado na forma de procedimentos referentes às aulas para professores, processos administrativos para os coordenadores, datas e eventos importantes, etc. Há ainda os textos que podem ser classificados como testemunhos pessoais ou diários, uma vez que, por meio destes, professores e coordenadores compartilham suas experiências ligadas ao ensino e também aos anos de trabalho dentro da instituição.

Com relação aos vídeos encontrados no website, são classificados de maneira a serem acessados como no formato "programa de televisão". Assim, eles são classificados a partir de seus títulos, o que especifica a temática de cada um: a realidade de sala de aula, procedimentos e situações do dia a dia do professor; diferentes metodologias de ensino, história e conceitos referentes à linguística e educação,mais especificamente ao ensino da língua inglesa; utilização da língua inglesa, apresentando questões fonéticas, gramaticais, lexicais, etc.; testemunho de professores $\mathrm{e}$ coordenadores e suas experiências em sala de aula; questões ligadas à gestão de sala de aula e da escola por parte dos professores e coordenadores.

Para a específica análise linguística deste trabalho,foram escolhidos um texto e um vídeo do website. Abaixo são expostas as transcrições de cada um.

P\&D desenvolve curso voltados aos coordenadores.

O departamento de P\&D, sob a direção de Márcio, busca, constantemente, o aperfeiçoamento de suas técnicas de ensino, metodologia e sala de aula. Dessa vez, pensando nos coordenadores, um novo curso foi desenvolvido, visando, como sempre, aprimorar a qualidade do trabalho dos profissionais da rede.

"O nosso intuito é oferecer, todos os meses, um curso sobre assuntos específicos relacionados à coordenação para que o profissional esteja sempre se desenvolvendo", afirma Márcio. O primeiro curso está perto de acontecer e, para a turma inicial, 10 coordenadores já foram selecionados.

De acordo com o Diretor, a duração será de 10 dias, envolvendo tarefas via web, Skype sessions e observação em sala de aula e, para se chegar à estrutura ideal, foi realizada uma pesquisa. "O 
departamento de revisão fez o trabalho em campo, pesquisando, em cada escola; depois, eu formatei com a Elisa o conteúdo do programa”, revela Márcio.

Olá pessoal, eu estou aqui para falar de um novo programa, Programa X, que é parte do lançamento do novo [website]. Nós pensamos neste programa porque eu acredito que nós educadores, nós lidamos com pessoas. E existe algo chamado administração que eu acredito que é muito importante em nossa tarefa diária. Quero dizer, nós professores administramos alunos, coordenadores administram professores e precisamos falar sobre este tópico porque não podemos dar por certo que é fácil, que é auto-explicativo como lidar com pessoas. Não é. Então precisamos abordar este tópico e pensamos neste programa para fazer isto. Nós vamos focar em administração do tempo e administração de conflitos. E claro que você pode pensar em situações, como professores ou coordenadores, nas quais você deve administrar o tempo, você tem que decidir suas prioridades, você tem que decidir o que vai deixar para o dia seguinte, ou como você resolve conflitos entre alunos, entre professores, entre você e outra pessoa. Estes serão alguns assuntos sobre os quais nós vamos falar aqui, mas nós vamos fornecer teoria, teorias e ideias para ajudar você no seu trabalho diário. Este é o propósito de nosso programa aqui. Nós não queremos pensar que administração é algo que nascemos sabendo, não nascemos, ok? É algo que você aprende conforme você lê, conforme você debate, conforme você administra também. Então é algo que você... é uma habilidade que você aprende, é nisto que acreditamos, certo? Nós teremos apresentadores diferentes, nós teremos aqui todos os coordenadores regionais e também os instrutores. E talvez eu apareça de vez em quando para falar sobre administração também. É um programa muito importante, algo novo, nós temos um layout aqui, vocês veem [apontando para o cenário], e nós pensamos nele porque nós queremos tratar do assunto com seriedade, nós queremos tratar, você sabe, que lidar com pessoas e cuidar de pessoas é algo realmente importante e nós precisamos falar sobre isto, certo? Então é Programa X, é o seu investimento pessoal. (tradução nossa) $)^{5}$

Seguindo a análise a partir dos conceitos de Feitosa (1998) sobre escritos de trabalho, percebe-se que na internet os textos apresentam uma materialidade diferente, considerando sua permanência ou efemeridade. Isso porque esta mídia funciona como um enorme banco de dados, capaz de armazenar tudo aquilo que os administradores dos servidores consideram pertinente. Issodiz respeito a possível comparação entre as versões impressa e virtual de um mesmo texto.O mesmo pode-se dizer dos textos orais, sejam eles divulgados através de vídeos ou programas de chat, pois em ambas as

\footnotetext{
${ }^{5}$ Texto original: "Hello guys, I'm here to talk about a new program, Program $\mathrm{X}$, which is part of the release of the new [website]. We thought about this program because I guess we educators, we deal with people. And there is something called management which I guess is very important in our everyday task. I mean, we teachers we manage students, coordinators manage teachers and we need to talk about this topic because we cannot take for granted that it's easy, that it's self explanatory how to deal with people. It's not. So we need to address this issue and we thought about this program to do so. We're going to focus on management of time and management of conflicts. And of course you can think about situations, as teachers or as coordinators, in which you have to manage time, you have to decide your priorities, you have to decide what you're gonna leave for the next day or how you solve conflicts between students, between teachers, between you and someone else. These are the issues we're gonna talk about here, but we're gonna provide you with theory, theories and ideas to help you in your everyday work. That's the purpose of our program here. We don't wanna think that management is something that you born knowing, no you were not, ok? It is something that you learn as you read, as you debate, as you manage as well. So it's something that you... it's a skill you learn, that's what we believe, alright? We're gonna have different presenters, we'll have here all regional coordinators and also the trainers presenting this program. And maybe I'll show up once in a while to talk about management as well. It's a very important program, something new, we have a layout here, you see, and we thought about it because we wanna take it seriously, we wanna take that, you know, dealing with people and taking care of people is something quite important and we need to talk about that, alright? So it's Program X, it's your personal investment."
} 
situações há a possibilidade de gravação. Dessa maneira, percebe-se que a internet e as tecnologias digitais, de forma geral, contribuem para a permanência e o registro dos textos por tempo indeterminado.

E ainda, segundo as concepções de Feitosa (1998), pode-se enquadrar todo o conteúdo do website do Grupo O nas categorias de escritos operacionais, gerenciais ou formativos, pois tanto os textos quanto os vídeos tratam de questões instrutivas, normativas ou mesmo capacitadoras. Consequentemente, acontece que este website é uma grande ferramenta comunicacional para a divulgação daquilo que foi compreendido anteriormente como trabalho prescrito, a partir das elaborações de Brito (2008) e Freitas (2011), pois ali são apresentadas informações e instruções sobre aquilo que é considerado adequado na realização do trabalho dentro da área de ensino do grupo.

Além disso, avaliando propriamente a atividade de linguagem apresentada no website, também é possível considerar que ali são encontrados exemplos claros tanto de linguagem como quanto no e sobre o trabalho, a partir daquilo que foi mencionado anteriormente ao serem citados Lacoste (1998) e Nouroudine (2002). A linguagem como trabalho acontece quando a própria língua, que é o "bem" vendido pela empresa, é o material evidenciado nos textos, o que acontece principalmente através dos vídeos referentes à utilização da língua inglesa. A linguagem sobre o trabalho é aquela também revelada nos textos operacionais, gerenciais e formativos, pois permite a transmissão de saberes entre os diferentes funcionários. Já a linguagem no trabalho acontece através da possibilidade que os vários usuários do website têm de interagir, ao deixar comentários em um texto ou em um vídeo.

Passando então para a análise do corpus a partir de seus elementos linguísticos propriamente ditos, deve-se considerar a cena de enunciação formada pelo conjunto dos dois textos selecionados. Dessa maneira, inicialmente, percebe-se que a voz da empresa, o enunciador em questão, é formada por várias vozes individuais, que ratificam a posição da instituição. Isto acontece principalmente ao serem citados o departamento de pesquisa e desenvolvimento (entidade máxima do departamento de ensino neste contexto),bem como uma de suas integrantes (Elisa) e seu diretor geral (Márcio), o qual ainda serve de fiador (MAINGUENEAU, 2008b) da cena particular instaurada pelo vídeo "Programa X".

Dessa forma, fica clara a imagem de um fiador de autoridade, baseada em uma boa reputação que parece ter sido construída por este departamento de pesquisa e desenvolvimento ao longo do tempo, e que é referenciada e evidenciada quando no discurso são tratados assuntos relativos à qualificação profissional dos demais colaboradores da área de ensino da empresa. Esse fiador incorpora discursos da instituição, a qual parece estar plenamente ciente de que a constante e cuidadosa gestão dos funcionários e da educação gera resultados positivos para a mesma.

Assim, considerando a análise do estatuto do enunciador e do enunciatário (MAINGUENEAU, 2008a), percebe-se a estruturação de uma imagem saliente por parteda empresa como enunciador: a da importância da constante qualificação profissional por parte de seus funcionários. A partir dessa imagem, a empresa idealiza que seus colaboradores, para desempenhar suas funções com sucesso, devem prestar constantemente atenção na sua capacitação no ambiente de trabalho.Verifica-se então 
que, a partir da cenografia construída, deriva um ethosno qual a posição de poder do diretor do departamento de ensino aparenta não impor uma forma de ser, mas sim sugerir, pois este fiador assume a posição de funcionário modelo que tenta motivar os outros colaboradores a adotarem a mesma postura dentro da empresa. Logo, pode-se dizer que este é, sim, um ethos coercivo, mesmo que essa tentativa de convencimento ocorra de forma indireta ou velada.

É possível ainda perceber a força de persuasão que a empresa espera deMárcio, diretor do departamento de ensino, pois ambos os textos fazem menção a ele, o qual é o verdadeiro fiador, que incorpora esta imagem da empresa (enunciador) construída pelos funcionários que acessam o website (coenunciadores).Logo, a cenografia enunciativa revela a imagem de uma empresa que possui como qualidade principal uma verdadeira preocupação com oensino. E, ao mesmo tempo, é construído nos enunciados da empresa o arquétipo de funcionário para trabalhar nela: comprometido com seu próprioprocesso de ensino visando crescimento pessoal e profissional (deve participar dos cursos oferecidos pelaorganização, ler os textos e assistir aos vídeos disponibilizados para sua qualificação especializada).Este ethos discursivo da empresa está engendrado na cenografia enunciativa, a qual também destaca a notoriedade da companhia pelo trabalho realizado até então, e dessa forma o poder de liderança que o departamento de pesquisa e desenvolvimento tem sobre os outros funcionários da área de ensino, mediante discursos que enfatizam a forma de gerenciar este departamento.

Com relação à dêixis enunciativa, que institui o tempo e o espaço no discurso (MAINGUENEAU, 2008a), as marcas linguísticas apresentadas nos textos referem-se a um presente que aponta o porvir com a ênfase à ideia de novidade, inovação, melhoria no espaço discursivo do aqui. O tempo da enunciação é estabelecido com o uso da cronografia em expressões como:constantemente, todos os meses e perto de acontecer; também são utilizadas formas verbais que identificam o futuro:será, serão, teremos, vamosfocar, vamosfalar e vamosfornecer.Dessemodo, não importa se este aqui é o local onde a empresa, o departamento de ensino ou departamento de pesquisa e desenvolvimento estão situados ou o website site está armazenado. O que importa é que este aqui é o local onde os funcionários da empresa podem encontrar capacitação profissional.

Além disso, através de outras marcas linguísticas, ainda é possível identificar o modo de enunciação e assim reconhecer o tom do texto. É interessante notar, por exemplo, que apesar de ambos os textos tratarem de uma clara prescrição de trabalho (os cursos que devem ser feitos, os assuntos que devem ser estudados, etc.) não há o predomínio de formas verbais deônticas, mas sim de formas epistêmicas que expressam certeza.Issoreforça o que foimencionado anteriormente com relação à autoridade do departamento de pesquisa e desenvolvimento e de seu diretor, capaz de persuadir por sua boa reputação epelo fato de estar marcado em seus enunciados a importância da constante aquisição de novos conhecimentos e a necessidade dese atualizar profissionalmente.

Conclui-se então que o website do departamento de ensino do GrupoO está de acordo com aquilo que Maingueneau (2010) chama de hipergênero, remetendo às diversas cenografias possíveis de serem apresentadas em uma página de internet, ainda 
mais pela multiplicidade de semioses ao serem colocados lado a lado textos, vídeos, fotos, etc. De qualquer forma, é necessário afirmar que também há uma cenografia geral do website, depreendida ao ser considerado o website na sua totalidade, visto ser esta a ferramenta por meio da qual a empresa tem contato direto com seus funcionários da área de ensino. É nesse processo comunicacional, então, que se estabelece o ethos discursivo do enunciador, o qual está ciente que para aumentar seus rendimentos financeiros é necessário investir na constante qualificação de seus colaboradores. Contudo,esseethos também demonstra que a maneira de garantir esta qualificação não é pela imposição da diretoria da empresa, mas sim pela persuasão através da imagem de um fiador que serve como modelo de profissional a ser seguido. O coenunciador então legitima este discurso ao incorporar a imagem do fiador e constituir a imagem de funcionário ideal, o qual está de acordo com as prescrições estabelecidas nos enunciados encontrados no website.

\section{6)Considerações finais}

A análise interdisciplinar aqui proposta, relacionando práticas de linguagem em situações de trabalho e ergonomia da atividade com semântica global e os conceitos de cenografia e ethosdiscursivo, teve Feitosa (1998), Lacoste (1998), Nouroudine (2002), Souza-e-Silva (2002) e Trinquet (2010) como principais referências sobre o uso da linguagemcomo, sobre e no trabalho, sobre escritos no trabalho, trabalho prescrito e também sobre adisciplina ergológica. Para tratar especificamente das questões referentes ao ethos discursivo e à cenografia, com base nos planos constituintes da semântica global, o referencial teórico partiu dos estudos empreendidos por Maingueneau (2006, 2008a, 2008b, 2008c, 2010, 2011).

Este estudo, que visou tratar sobre textos veiculados em um website corporativo, foi delimitado em avaliar a situação de trabalho estabelecida por tais textos, além de identificar a cenografia criada pelo website bem como o ethos discursivo da empresa na condição de enunciadora. Percebe-se assim que através da internet há uma mudança na noção de escritos de trabalho, principalmente no que se refere a uma possível efemeridade ou permanência destes textos, visto que esta mídia permite armazenamentos praticamente ilimitados e garante reutilização de tais textos. Além disso, esses textos, que tanto podem ser operacionais, quanto gerenciais ou formativos, e que tanto se referem à linguagem como, no ou sobre o trabalho, configuram-se evidentemente como formas de a empresa prescrever o trabalho que espera de seus funcionários. E dentro desta situação,o espectador mais desatento pode construir a imagem simplista de uma empresa que se preocupa com a qualificação profissional de seus funcionários. Porém, com um olhar mais atento, percebe-se que, em realidade, a importância desta qualificação é constantemente enfatizada, em todos os momentos que a empresa enunciadora recorre à figura de seu fiador mais proeminente, o diretor da área de ensino e do departamento de pesquisa e desenvolvimento da empresa. Esse fiador, mesmo não impondo essa visão da empresa na forma de ordens, ratifica aquilo que é prescrito através do seu prestígio, e assim também cria a imagem do coenunciador, o funcionário que acessa o website e se constitui como funcionário ideal ao colocar em prática tais estratégias de qualificação. 
Além disso, este trabalho pretende contribuir com o estudo sobre novas ferramentas comunicacionais colocadas a serviço de situações de trabalho e também com a análise de práticas linguageiras a partir delas. Ademais, também sugere-se um aprofundamento no que diz respeito à aplicação do método ergológico nestas situações em que empresas utilizam a internet como plataforma de trabalho, bem como um aprofundamento na questão da conceituação dos hipergêneros (MAINGEUNEAU, 2010), referentes às cenografias criadas por websites que proporcionam maior interatividade com o usuário a partir da utilização das ferramentas disponíveis com a tecnologia da Web 2.0.

\section{Referências}

BRITO,J. C. Trabalho Prescrito. In: PEREIRA, I.B.; LIMA, J.C.F. Dicionário da educação profissional em saúde. 2.ed. rev. ampl. Rio de Janeiro: EPSJV, 2008.

CHARAUDEAU, Patrick; MAINGUENEAU, Dominique. Dicionário de análise do discurso. 3. ed. São Paulo: Contexto, 2012.

FACIN, D. O enlaçamento enunciativo de um ritual carnavalizado: cenografia e ethos discursivo em sambas-enredo de escolas carnavalescas do meio-oeste catarinense. 2012. 120 f. Dissertação (Mestrado em Letras) - Universidade de Passo Fundo, Passo Fundo, 2012. Disponível em: <https://secure.upf.br/pdf/2012DeboraFacin.pdf>. Acesso em: 20 out. 2013.

FEITOSA, V. Escritos de trabalho: recortes analíticos. In: Linguagem e trabalho. Rio de Janeiro: Lucerna, 1998. p. 37-50.

FREITAS, E. C. Linguagem na atividade de trabalho: ethos discursivo emeditoriais de jornal interno de empresa. Desenredo, Passo Fundo, v. 6, n. 2, p. 170-197,jul./dez. 2010 .

Cultura, linguagem e trabalho: comunicação e discurso nas organizações.Desenredo, Revista do Programa de Pós-Graduação em Letras da Universidade de PassoFundo, v. 7, n. 1, p. 104-126, jan./jun. 2011.

HISTORY. Ergoweb. Disponível em <http://ergoweb.com/knowledge/ergonomics101/history/>. Acesso em: 16 set. 2014.

International Ergonomics Association. Disponível em: <http://www.iea.cc/01_what/ Whatis Ergonomics.html>. Acesso em 21 out. 2013

LACOSTE, M. Fala, atividade, situação. In: Linguagem e trabalho. Rio de Janeiro: Lucerna, 1998. p. 15-36.

MAINGUENEAU, D. O discurso literário. São Paulo: Contexto, 2006. . (1984). Gênese dos discursos. São Paulo: Parábola Editorial, 2008a. 
Ethos, cenografia e incorporação. In: AMOSSY, Ruth. Imagens de si no discurso: a construção do ethos. São Paulo: Contexto, 2008b. p. 69-92.

Problemas de ethos. In: Cenas da enunciação. São Paulo: Parábola Editorial, 2008c. p. 55-73.

Hipergênero - Hipergênero, gênero e internet. In: Doze conceitos em análise do discurso. Sírio Possenti e Maria Cecília Perez de Souza-e-Silva (Org.). São Paulo: Parábola Editorial, 2010, p. 129-138.

Análise de textos de comunicação. $6^{\text {a }}$ ed. São Paulo: Cortez, 2011.

NOUROUDINE, A. A linguagem: dispositivo revelador da complexidade do trabalho. In: SOUZA-E-SILVA, Maria Cecília P.; FAÏTA, Daniel (Orgs.) Linguagem e trabalho:construção de objetos de análise no Brasil e na França. São Paulo: Cortez, 2002. p. 17-30.

SOUZA-E-SILVA, M. C. A dimensão linguageira em situações de trabalho. In:SOUZA-E-SILVA, Maria Cecília P.; FAÏTA, Daniel (Orgs.) Linguagem e trabalho: construção de objetos de análise no Brasil e na França. São Paulo: Cortez, 2002. p. 6176.

TRINQUET, P. Trabalho e educação: o método ergológico. Revista HISTEDBR Online,Campinas,n. esp., p. 93-112, ago. 2010. 